\title{
Tests of a SI engine powered by gaseous fuels blends of LPG + DME of various proportions with variable load
}

ARTICLE INFO

Received: 19 September 2021 Revised: 15 November 2021

Accepted: 22 November 2021

Available online: 5 December 2021
The article presents the test stand and the test results of a vehicle with an SI engine, fueled by a blends of LPG and DME gaseous fuels. During the tests, a chassis dynamometer was used, which reproducibly reflected road conditions. The tests were carried out for various shares of $D M E$ in the mixture, thus determining the maximum possible share of this fuel. The measuring points have been extended with different engine loads and different rotational speeds. The analysis of the pressure inside the engine cylinder made it possible to compare the operation of the engine powered by mixtures of different proportions to the reference fuel-LPG.

Key words: combustion process, fuel consumption, gaseous fuel blends, ignition correction, engine load

This is an open access article under the CC BY license (http://creativecommons.org/licenses/BY/4.0/)

\section{Introduction}

The ever-increasing demand for conventional motor fuels has also increased the interest in alternative fuels. Their market share is all the more significant, the more stringent exhaust emission standards that new car manufacturers throughout the European Union have to face. Alternative fuels, apart from the possibility of powering engines, must meet other criteria, including the two most important ones - ecological and economic assessment. The emissivity assessment is primarily influenced by the amount of harmful and toxic substances in the products of the combustion process. Their amount must be lower than that derived from the combustion of conventional fuels. The economic assessment is carried out in relation to conventional fuels and in the absence of measurable benefits for users, it is not possible to adopt such energy carriers on a wide scale of the market [1].

The current, very intensive development of alternative drives has, in a sense, verified the requirements set by lawmakers and also by the society. The pursuit of broadly understood eco-mobility began to be perceived on a larger scale. It is primarily the awareness of emissions from the entire life cycle of fuel - from its extraction, processing, distribution, to combustion products in an internal combustion engine. A similar approach applies to electric and hybrid vehicles that require external charging. Currently, the electricity used to charge these vehicles comes largely from non-renewable sources. As a result, the carbon footprint remains at a similar level as in the case of fully conventional drives. However, a significant advantage of battery powered vehicles is the fact that there is no local emission. Electric vehicles, the way of use of which is assigned to a given location, resulting from their use in urban areas, are not so burdensome for the environment. This is due to the lack of exhaust fumes and significantly lower noise. Examples of such vehicles are public transport buses or other public transport vehicles, vehicles used for the purpose of serving the urban economy or transport companies that perform the so-called last mile transport. Non-urban emis- sions in the case of generating electricity for EVs do not affect the deterioration of air quality in the city center, which significantly improves the quality of life of its inhabitants. However, the above benefits do not have an impact on total emissions as long as electricity is not obtained to a greater extent from renewable sources or the fuels burnt are replaced by fuels with a reduced share of coal. Another current problem of electric vehicles is energy storage. Currently available batteries often do not provide half of the vehicle's real range compared to conventionally powered vehicles. The development and use of electric vehicles also depend on the expansion of the infrastructure for charging and servicing such vehicles. Therefore, an important activity is the simultaneous development of alternative fuels. The global increase in fuel demand is related to the further development of fuels derived from renewable sources as well as from fossil sources.

\section{Preparation of fuel blends}

Alternative fuels also include mixtures of gaseous fuels. An example of this type of mixtures can be the mixture of LPG and DME presented in the following study. LPG, a mixture of propane and butane, is produced from crude oil in the refining process. Due to the fact that it is derived from fossil raw materials, its production, availability and scope of application are limited. The lower proportion of carbon in relation to gasoline gives about $10 \%$ lower carbon dioxide emissions.

DME is an organic chemical compound from the ether group, colorless with a characteristic odor, flammable and explosive, moderately soluble in water. It can be produced from fossil resources such as natural gas or hard coal, as well as from biomass, then it is referred to as bioDME. Currently, dimethylether is used in the energy and cosmetics industries, as well as in transport as a fuel for diesel engines, due to the high cetane number - 55 [2].

The similar physical and chemical properties of both fuels allow them to be mixed, safely stored, and used as fuel in an SI engine [3-5]. 
The production of mixtures on the stand included the preparation of fuel for experimental tests on a chassis dynamometer. It consisted in refueling the mixture components - LPG and DME into a common tank. First, fuel with a higher mass fraction was refueled in order to calculate the necessary mass fraction of the second fuel in the next step. The mass fraction of the second fuel (DME) differed depending on the need to obtain a specific mixture. The tank for the mixture was placed on an electronic scale with an accuracy of 1 gram. Also during the tests of the vehicle on the chassis dynamometer, the tank was placed on the scales, which made it possible to measure fuel consumption in oneminute intervals. The vehicle was powered by connecting the fuel tank to the gas reducer, using a cable for automotive gas installations. The construction of the stand is shown on the diagram (Fig. 1) and in the photo (Fig. 2).

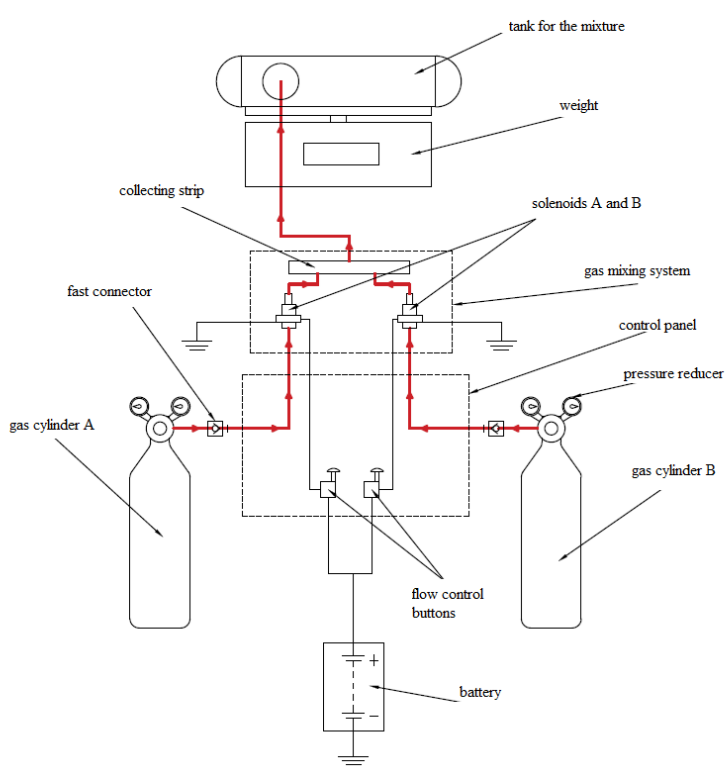

Fig. 1. Diagram of the station for the production of a gas mixture [6]

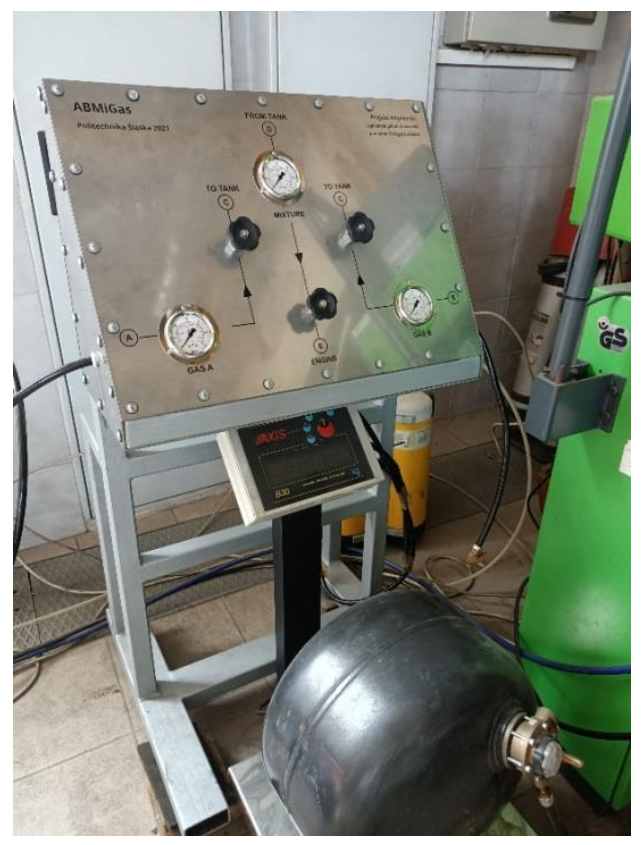

Fig. 2. Station for the production of gas blends
Based on the experience gained from the first series of tests, a stand for the production of gas mixtures was designed. The stand facilitated and shortened the time of preparing the mixture for testing. Needle valves were used for its construction, which are characterized by high accuracy during their control.

\section{The object of research, research apparatus and the scope of the research carried out}

The object of the research was an Opel Astra passenger car with an engine capacity of $1.6 \mathrm{dm}^{3}$, factory-adapted to run on unleaded petrol. The engine was equipped with an LPG gas installation. The installation does not require special adaptation to be supplied with LPG and DME mixtures, except for the possible replacement of seals, due to the possible adverse effect of DME on rubber elements.

Experimental tests were carried out on a Bosch FLA chassis dynamometer with an eddy current brake. This made it possible to measure the engine torque, power and also the speed of the vehicle. The dynamometer reflected the conditions of the vehicle moving along the road along with its resistance, additionally providing full repeatability of the measurement. The vehicle engine is equipped with the indicated pressure measurement circuit. The pressure was measured on the first cylinder using a Kistler 6121 pressure sensor which was coupled to a spark plug. The pressure sensor was connected to the charge amplifier and data acquisition system. Additionally, a marker with a photo sensor is mounted on the pulley. Thanks to it, it was possible to synchronize the position and speed signal of the crankshaft with the pressure signal.

The first stage of the research included mixtures with a DME percentage of $7,11,14,17,21 \%$. The tests were carried out for various engine loads and selected rotational speeds. Mass measurement of fuel consumption was performed for all measurement points, the pressure indicated in 150 consecutive engine operation cycles was recorded and the exhaust gas temperature was measured in the engine exhaust manifold.

During the tests, the spark advance angle was also corrected. All measurement series were repeated three times; with factory settings and with corrections increasing the value of the spark advance angle by $3^{\circ}$ and $6^{\circ}$.

Based on the analysis of the results collected at this stage of the research, an assessment of the combustion process was performed, which did not show any clear disturbances in the engine's operation. Therefore, it was decided to extend the scope of the tests to include further mixtures, where the DME percentage was 26 and 30\%, respectively.

\section{Development of measurement results}

\subsection{Fuel consumption measurement}

Fuel consumption, determined by the mass method, was measured with an accuracy of 1 gram during one minute for each measuring point. The results of the measurements are presented in graphs (Fig. 3-5) for different levels of the spark advance angle.

The measurements were repeated for the changed engine controller settings, for the spark advance angle correction of 3 and $6^{\circ}$. 


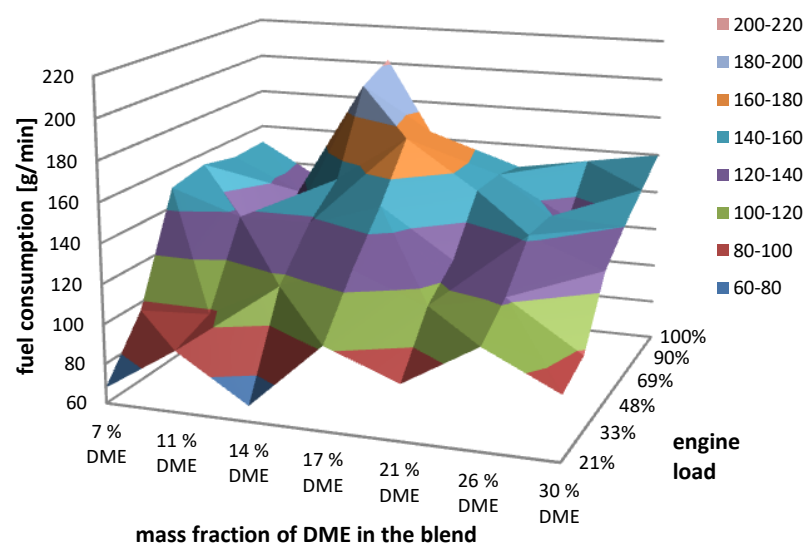

Fig. 3. Fuel consumption $[\mathrm{g} / \mathrm{min}]$ depending on the percentage of DME and engine load, no correction of the spark advance angle

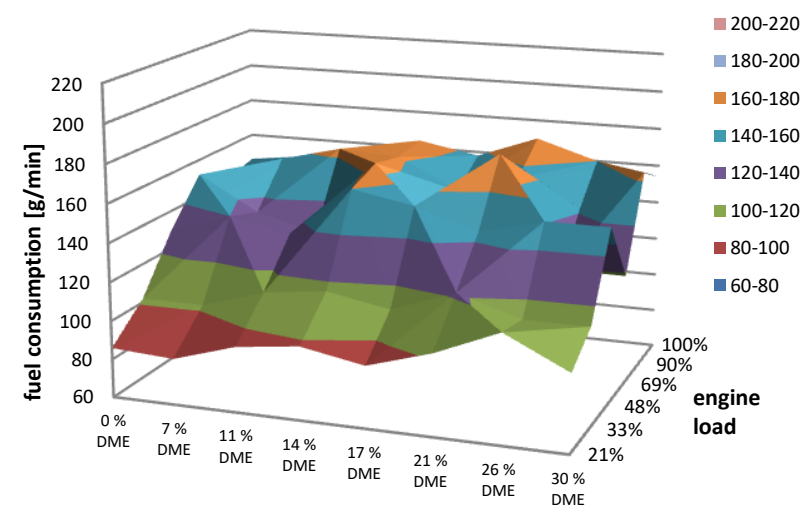

mass fraction of DME in the blend

Fig. 4. Fuel consumption [g/min] depending on the percentage of DME and the engine load for the correction of the spark advance $3^{\circ}$

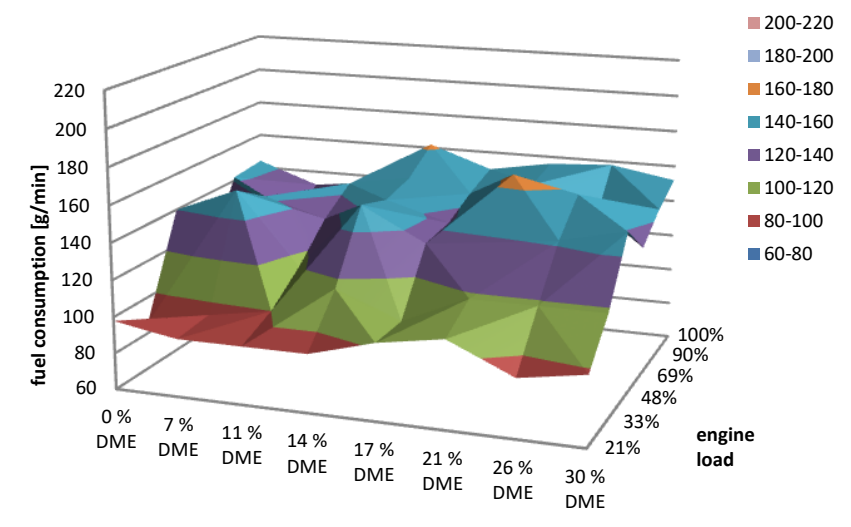

mass fraction of DME in the blend

Fig. 5. Fuel consumption $[\mathrm{g} / \mathrm{min}]$ depending on the percentage of DME and the engine load for the correction of the spark advance $6^{\circ}$

On the basis of the above charts, it can be observed that in an LPG-fueled engine, due to the slower combustion process compared to gasoline, a larger spark advance angle should be used. In the case of the mixture of LPG and DME, this relationship also occurs. For a correction by an additional 3 steps, fuel consumption decreased noticeably. Compared to the serial settings, the greatest changes were recorded for mixtures of 11 and 14\% DME at partial and maximum loads. On the other hand, for the $30 \%$ mixture, the greatest differences occur at the half load of the engine. With an ignition correction of 6 degrees, an even greater benefit in fuel economy is achieved. It decreased evenly over the entire range of engine loads for all mixtures.

Fuel consumption, determined by the mass method, was measured with an accuracy of 1 gram during one minute for each measuring point. The results of the measurements are presented in graphs (Fig. 3-5) for different levels of the spark advance angle.

\subsection{Changes in the combustion process}

The measuring equipment described above made it possible to register the pressure inside the engine cylinder. For each measuring point, 150 engine cycles were recorded in succession. The collected data was statistically processed using the EnComAn [7] program, thus extracting a sample representative for each measurement point. Further analysis consisted in determining the boundaries of the combustion process. At this stage, the computational capabilities of the Diadem NI program were used. Using the developed model [8], on the basis of the designated sample representative of the pressure course for the recorded work cycles, the polytrope and pressure increases as a function of the crankshaft rotation angle were calculated.

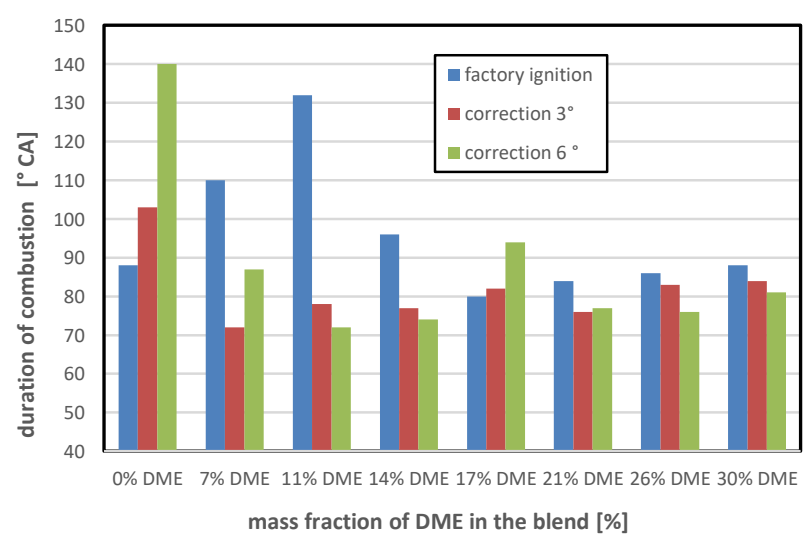

Fig. 6. Summary of the duration of combustion processes for the engine speed of $3000 \mathrm{rpm}$, fueled with LPG-DME mixtures, with the correction of the ignition angle. Engine load 33\%

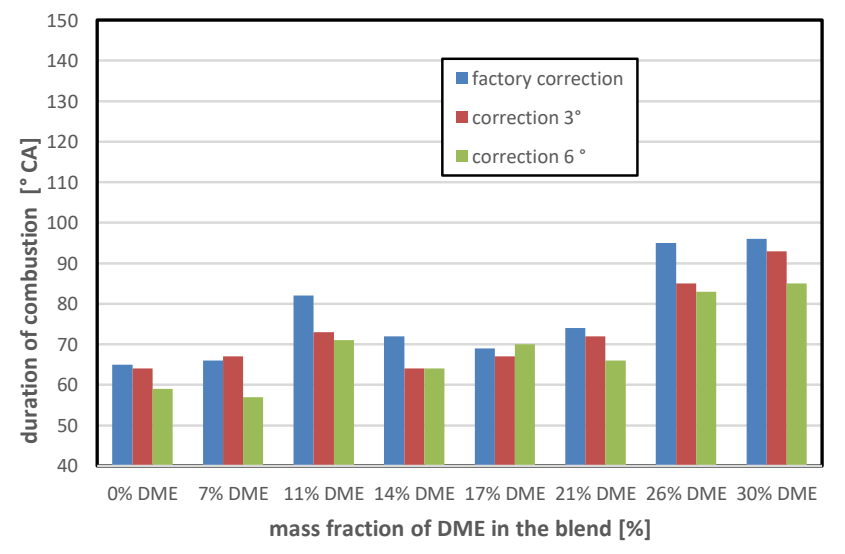

Fig. 7. Summary of the duration of combustion processes for the engine speed of $3000 \mathrm{rpm}$, fueled with LPG-DME mixtures, with the correction of the ignition angle. Engine load 69\% 
After determining the boundary assumptions, the combustion process in relation to the angle of rotation of the crankshaft was identified.

The results are presented by means of column charts (Fig. 6-8). The analysis of the charts made it possible to compare the length of the combustion processes for different shares of DME in the mixture for the levels used in the research. ignition timing corrections by 3 and 6 degrees, respectively, in relation to the serial settings.

The combustion period is understood as the part of the crankshaft rotation, expressed in degrees $\left[{ }^{\circ} \mathrm{CA}\right]$, between the positions of the crankshaft, for which the applied thermodynamic model performs an additional energy increase, which proves the combustion process taking place.

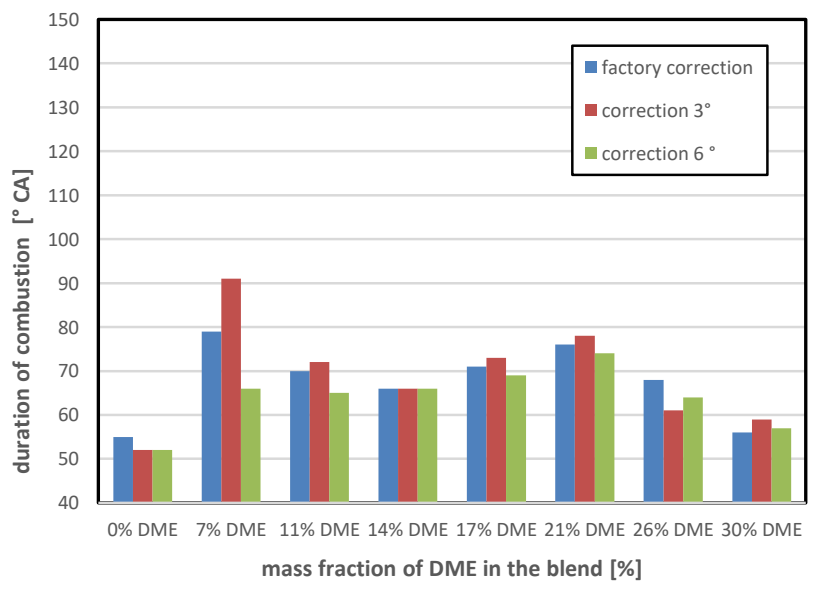

Fig. 8. Summary of the duration of combustion processes for the engine speed of $3000 \mathrm{rpm}$, fueled with LPG-DME mixtures, with the correction of the ignition angle. Engine load 100\%

\section{Conclusions}

Based on the results of the research, the following conclusions were drawn:

- Plane graphs made it possible to compare fuel consumption for mixtures with increasing DME share as a function of engine load for serial engine settings and for two corrections

- Extending the ignition time, reducing fuel consumption, especially for engine loads above $48 \%$

- The greatest benefits from the spark advance correction were obtained for a mixture with a mass fraction of DME 14 and $17 \%$

- The graphs made it possible to compile representative combustion processes when fueling the engine with gaseous fuel with different DME mass fractions, for different engine loads and two additional settings of the spark advance angle

- The greater the engine load, the shorter the combustion process

- For the engine load of $69 \%$, increasing the SA shortened the combustion process for all mixtures

- For the engine load of $69 \%$ when the engine was powered with a mixture of 26 and $30 \%$ DME, the combustion process was extended by approximately $30 \%$

- With the engine load of $33 \%$, the SA correction had an effect on the shortening of the combustion process, in addition to the mixtures of $100 \%$ LPG and $17 \%$ DME

- For $100 \%$ engine load, the shortest combustion process was recorded for fueling the engine with reference fuel and mixtures with the highest share of DME

- At maximum engine load, the SA correction did not have a significant effect on the duration of the combustion process for all tested mixtures

\section{Nomenclature}

DME dimetyloeter

SA spark advance
LPG liquified petrolum gas

SI spark ignition

\section{Bibliography}

[1] BRZEŻAŃSKI, M., JUDA, Z. Napędy hybrydowe, ogniwa paliwowe i paliwa alternatywne. Elektrotechnika i elektronika samochodowa. Robert Bosch GmbH. WKt Warszawa 2010.

[2] SHI, L., C, JI, WANG, S. et al. Combustion and emissions characteristics of a S.I. engine fueled with gasoline-DME blends under different spark timings. Fuel. 2018, 211(1), 1117. https://doi.org/10.1016/j.fuel.2017.09.019

[3] YOON, E.S., HAN, C. A review of sustainable energy recent development and future prospects of dimethyl ether (DME). Computer Aided Chemical Engineering. 2009, 27, 169-175. https://doi.org/10.1016/S1570-7946(09)70249-4

[4] ARCOUMANIS, C., BAE, C., CROOKES, R. et al. The potential of di-methyl ether (DME) as an alternative fuel for compression-ignition engines: A review. Fuel. 2008, 87(7), 1014-1030. https://doi.org/10.1016/j.fuel.2007.06.007

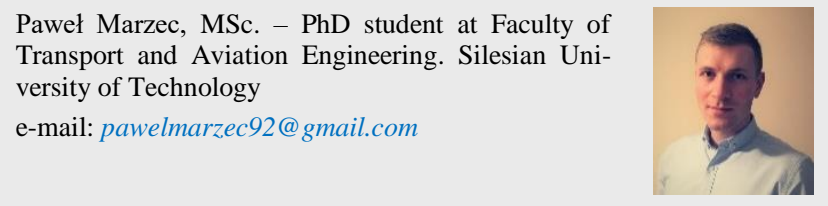

[5] LEE, S., OH, S., CHOI, Y. et al. Effect of n-butane and propane on performance and emission characteristics of an SI engine operated with DME-blended LPG fuel. Fuel. 2011, 90(4), 1674-1680. https://doi.org/10.1016/j.fuel.2010.11.040

[6] BYTOMSKI, D. Project of the system to preparing of fuel gas blends with a specified composition. Katowice. 2009. 57.

[7] KUBICA, G. Efektywność konwersji energii w silniku o zapłonie iskrowym zasilanym paliwami gazowymi o obniżonym udziale węgla. Publishing House of the Institute for Sustainable Technologies-National Research Institute in Radom, Radom 2013.

[8] NIŚCIÓR, A. Analysis of the combustion process in the stabilized working engine on the basis of indicated pressure. Politechnika Ślaska. Katowice 2008, 53-54. 